\title{
Role of Surfactant for the Treatment of Alveolar Cells against Coronavirus (Covid-19)
}

\author{
Sony Ahmed ${ }^{1}$, Md. Shamim Akter ${ }^{2}$, Kallol Roy ${ }^{3}$ and Md. Shafiul Islam ${ }^{3^{*}}$ \\ ${ }^{1}$ Department of Quality Control, Beximco Pharmaceutical Limited (US FDA Approved Pharmaceutical \\ Company), Gazipur-1700, Bangladesh. \\ ${ }^{2}$ Dept. of Public Health Engineering, Govt. of Bangladesh, Cox's Bazar, Bangladesh. \\ ${ }^{3}$ Dept. of Chemistry, Virginia Commonwealth University, Richmond, VA 23284, USA.
}

\section{Authors' contributions}

The work was carried out in collaboration among all authors. Author SA designed the study and wrote the first draft of the manuscript. Authors MSA and KR helped to search literature. Author MSI planned and analysed the study. All authors read and approved the final manuscript.

Article Information

DOI: $10.9734 / A R R B / 2020 /$ v35i630233

Editor(s):

(1) Paola Angelini, University of Perugia, Italy.

(2) Dr. Md. Torequl Islam, Federal University of Piaui, Brazil.

Reviewers:

(1) Talita Pilar Resende, IPEVE, Brazil.

(2) Deijanira Albuquerque, Federal University of Mato Grosso, Brazil. (3) Maicon Henrique Lentsck, Universidade Estadual do Centro Oeste, Brazil.

(4) Afsaneh Arzani, Babol University of Medical Sciences, Iran. Complete Peer review History: http://www.sdiarticle4.com/review-history/57720

Mini-review Article

Received 18 May 2020

Accepted 17 June 2020

Published 30 June 2020

\section{ABSTRACT}

Coronavirus disease (COVID-19) is an infectious disease caused by the newly discovered coronavirus. Coronavirus affects human lung tissues. Covid-19 should be infection of the lungs, the virus infects alveolar cells resulting in reduced production of pulmonary surfactant. Pulmonary surfactant is a complex of lipids and proteins that line the alveolar epithelial surface and stabilize it during respiration. The surfactant helps to reduce the surface tension on alveoli. The surface-active components of the alveoli are a complex mixture of specific lipids, proteins and carbohydrates, which is produced in the lungs by type II alveolar epithelial cells. As a result, the lungs continue to collapse, reducing its own volume, but the collapse is prevented by the muscles of inspiration, which instead increase its volume. Covid-19 allows the surfactant to maintain the correct amount of surfactant during the acute phase of infection during lung infection and allows time to resume and allow individual surfactant production for type II cells. Surfactant degradation or inactivation may 
contribute to increased susceptibility to pneumonia and increased susceptibility to infection. Surfactant deficiency in patients with acute respiratory syndrome in adults and surfactant administration may be a useful therapy against Covid-19.

Keywords: Surfactant therapy; Covid-19; respiratory distress syndrome; alveolar cells; surface tension.

\section{INTRODUCTION}

Covid-19 pandemic has spread around the world, but it is important to understand the virus's infection and its effects as it has become a pandemic disease. Covid-19 belongs to the coronavirus family, which also includes the SARS virus (Severe Acute Respiratory Syndrome) and the MERS (Middle East respiratory symptoms) virus. The coronavirus family includes strains of the virus that cause the common cold and flu. Covid-19 has been found to be closely related to SARS. SARS beta coronavirus, SARS-CoV, which caused the outbreak of SARS (Severe Acute Respiratory Syndrome) in 2003, and the new SARS-CoV--2, as a result in COVID-19 [1]. Covid-19 infection of the lungs, the virus infects alveolar cells resulting in reduced production of pulmonary surfactant Covid-19 affects the respiratory tract in humans. The infection starts with or without mild flu symptoms and progresses to more severe symptoms. Covid-19 is its effect on body systems, especially the lungs. Covid-19 mainly infects the lungs of infected people and in severe cases causes ARDS and pneumonia. It is important to remember that while it is not affected by RDS (Respiratory Distress Syndrome) and pneumonia in all cases, it is a phenomenon in most severe cases. Covid-19 directly affects the lungs and damages the alveoli (small air sacs). The function of the alveoli is to transfer oxygen to the blood vessels. These blood vessels or capillaries carry oxygen to the RBCs (Red blood cells). It is the RBCs that ultimately supply oxygen to all the internal organs of the body. Covid-19 works by damaging the walls and lining of the alveoli and capillaries. Debris from damage, causes plasma proteins to accumulate in the walls of the alveoli and thicken the lining. As the walls thicken, the transfer of oxygen to the red blood cells becomes obstructed. The denser the wall, the more difficult it is to transfer oxygen to the blood cells, making it difficult to breathe as the body continues to lack oxygen. And lack of oxygen to the internal organs causes a deficiency in the body and impairs the functioning of the organs. At this point, the body struggles to increase oxygen uptake. And the body's first response is to destroy the virus and prevent its replication, but if a person's immune system is weakened, the body is unable to stop the virus [2], and this exacerbates the crisis. Covid-19 has a tropical environment for epithelial cells and to replicate itself in the lungs, it infects alveolar II cells of the alveolar epithelium, which are efficient to replicate thus allowing the virus to replicate. The alveolar epithelium [3] contains I alveolar cells (squamous cells) [4,5] and II alveolar cells [6,7], and macrophages. According to squamous cells, the cells are very thin and, as a result, less numerous than the second type of cell, but they occupy about $95 \%$ of the surface of the alveoli. Squamous cells are responsible for respiratory exchange and are unable to replicate. Type II alveolar cells are able to replicate, providing growth to both type II alveolar cells and type I squamous alveolar cells. Alveoli can be compared to gas in water, because alveoli are wet and surround a central air space. Surface tension acts on the air-water interface and makes the bubble smaller (reducing the surface area of the interface). These organelles produce pulmonary surfactant $[8,9]$ and disperse into the alveolar space. Pulmonary surfactant is a surface-activated lipoprotein complex formed by type II alveolar cells. Proteins and lipids composed of surfactants have both hydrophilic and hydrophobic regions. The hydrophilic head group in the water and the hydrophobic tails protrude towards the air, absorbing at the airwater interface of the alveoli and reducing the surface tension. Surfactant production in humans begins in type II cells in the alveolar sac stage of lung development. Surfactants are substances that have the property of reducing surface tension, for example between liquids and air, allowing contact between the two. Covid-19 heavily interferes with surfactant production by infection type II alveolar cells. Lamellar bodies appear in the cytoplasm at 20 weeks gestation. These lamellar bodies are excreted by exocytosis in the surface layers of the alveolar airway lining, where surfactant tubular myelin mesh forms. Club cells also form a component of the lung surfactant [10]. People have been suffering from deadly infectious diseases for a 
long time, including viral outbreaks. Severe Acute Respiratory Syndrome Coronavirus-2 (SARS-Cov-2) is a newly identified virus that differs from the severe Acute Respiratory Syndrome Coronavirus (SARS-CoV) and Middle Eastern Respiratory Syndrome Coronavirus (MERS-CoV). However, it can because similar symptoms related to pneumonia [11,12]. Covid19 infection the second type of alveolar cells and consequently interferes with the production of surfactants. The amount of lungs obtained during a regular pulse-controlled inflation / removal indicates that the volumes obtained during flowering exceed a certain pressure exceeds the time during inflation. This difference in volume between inflation and deviation at a given pressure is called hysteresis, and is due to the surface-air-water pressure that occurs at the onset of inflation. However, surfactant reduces alveolar surface tension, as seen in premature infants suffering from respiratory tract infection syndrome. The normal surface tension for water is $70 \mathrm{dyn} / \mathrm{cm}(70 \mathrm{mN} / \mathrm{m})$ and in the lungs it is $25 \mathrm{dyn} / \mathrm{cm}$ (25 mN / m); however, after expiration, the compressed surfactant phospholipid molecules reduce the surface tension to a very low, near-zero level. Pulmonary surfactant thus greatly reduces surface tension, increases compliance and makes the lungs swell more easily resulting in reduced respiratory function. This reduces the pressure difference needed to allow the lungs to swell. Lung compliance decreases and ventilation decreases when lung tissue becomes diseased and fibrotic [13]. As the alveoli increase in size, the surfactant spreads further over the surface of the liquid. It effectively slows down the rate of alveoli expansion by increasing surface tension. This helps all the alveoli of the lung to expand at the same rate, as the faster it expands, the slower the rate of increase in surface tension. This means that the rate of contraction is more regular, so that the faster one shrinks in size, the lower the tension in the bottom, so that other alveoli can contract more easily. When the alveoli are smaller, the surfactant reduces the surface tension more easily because the surfactant is more concentrated. Representation of Pulmonary surfactant system are shown in Fig. 1.

According King and Clements, surfactant used in pulmonary medicine is a specific term that refer to the mixture of phospholipids, neutral lipids, and proteins recovered by alveolar lavage from animals, and has been best characterized by composition and surface properties $[14,15]$. The phospholipid and neutral lipid composition of the surfactant is relatively constant in mammal species and varies only during development or after acute lung injury [16-18]. Surfactants recovered by the alveolar wash method contain mainly plasma proteins as contaminants. Most of these sensitive proteins can be removed by the refining process and leave at least 2 classes of surfactant-specific proteins and their oligomers [19-21]. Characteristics of the alveolar surfactant complex are probably the result of the accumulation of multiple components of the surfactant in the second type of cell lamellar bodies, resulting in the formation of tubular myelin in the tubular hypo phase, and subsequently in the formation of tubular myelin. The general function depends not only on the composition but also on the organization of the components of the surfactant.

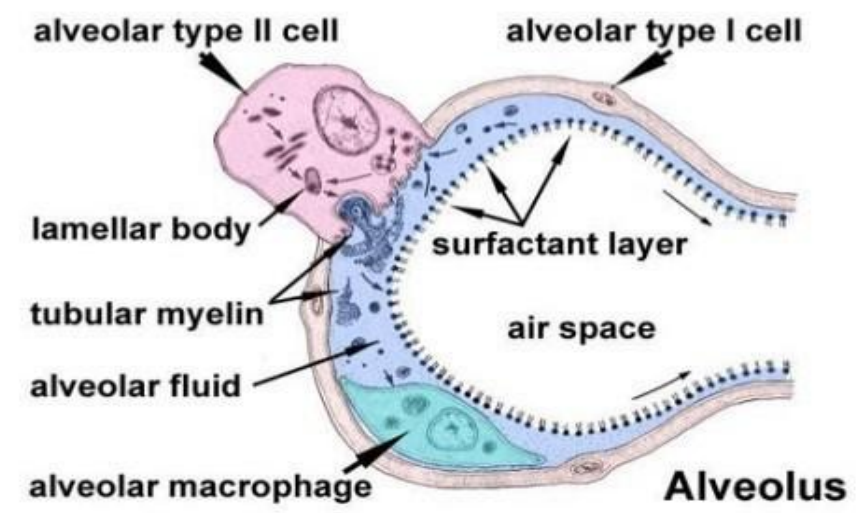

Fig. 1. Pulmonary surfactant system (https://images.app.goo.gl/ai2eX4992dHCMuBQA) 


\section{LITERATURE REVIEW OF SURFAC- TANT FUNCTION-THERAPY AGAINST LUNG DAMAGE}

After the onset of ventilation and the establishment of a functional residue capacity, the amount of surfactant present in the alveoli may be less important than preserving the activity of that surfactant. Very little is known about the surface properties of surfactants in children's alveoli and small airways with RDS (Respiratory Distress Syndrome). However, various studies suggest that the function may be abnormal. Surface features are abnormal in the presence of proteinaceous pulmonary edema [22]. Alveolar washes from lambs or infants with RDS (Respiratory Distress Syndrome) have very high to low surface tensions [23,24]. However, surfactants with great properties can be recovered in a simple centrifugation method. After very premature ventilation of lambs, a surfactant treatment will initially dramatically improve lung function. Surface tension of an alveolar wash surface will be comparatively less at the time of maximum response, but the excitation of the wash surface tensions of the lamb becomes even greater as develops respiratory failure again [25]. Despite the recurrence of respiratory failure, a large amount of surfactant with great surface properties can be recovered from alveolar washes by concentration. The soluble protein fraction of alveolar wash from lamb or specimens from the trachea of children with RDS (Respiratory Distress Syndrome) will disrupt the surfacetension-lowering properties of natural surfactant. Surfactant causes a clot when a thromboplastin and plasma are added. The presence of disrupted bronchial and alveolar epithelium and cell debris and hyaline membranes may not provide a satisfactory surface for surfactant function. The ability of the surfactant "type II cell" in preterm lungs with RDS (Respiratory Distress Syndrome) may be reduced. In short, there are many possibilities as to why surfactant function may be disrupted during the clinical course of RDS (Respiratory Distress Syndrome).

Treatment of the lungs with surfactant before the onset of spontaneous ventilation causes mechanical changes in the ventilation of the primary and all subsequent ventilator cycles. Spontaneous breathing by surfactant-deficient animals increases the amount of large tides, leaving the lungs unstable and empty at the end. In contrast, surfactant-treated lungs retain volume over the last period. This epithelial damage is the result of fluid filling, recurrent overdose of surfactant-deficient lungs and collapse of the small airways [26]. Hyaline membrane damage results from the coagulation of epithelial debris with proteins leaking from interstitial and vascular spaces of the lung through the epithelial barrier. Anatomical damage from spontaneous ventilation of the surfactantdeficient lung can be almost completely prevented by pretreatment with the surfactant prior to ventilation [27]. After intrathecal administration of the surfactant, histological changes were not observed even when the preterm pulmonary density increased with increased ventilation [28]. Surfactant not only improves aeration and compliance but also reduces bronchial epithelial lesions characterized by early pathological changes in RDS (Respiratory Distress Syndrome).

\section{RECAPITULATE AND RECOMMENDA- TION}

Surfactant therapy should be useful not only in the need for complementary surfactants, but also indirectly to who do not respond to a surfactant treatment. After a clinical assessment of the risks and benefits, in some cases it may be appropriate to administer surfactants even at the first signs of pulmonary dyspnea, making it necessary to insight before reaching the stage of dyspnea. Surfactant instillation can be done by a tracheal tube, a technique used in newborns with shortness of breath syndrome [29]. The surfactant of the intubated patient will be able to avoid subsequent influx of more frequently inflammatory fluid and substances into the pulmonary interstitium. The use of surfactants can prevent alveoli from breaking down and possibly improve their regeneration and lung gas exchange. In addition, the initial use of surfactants may limit the need for insights.

Our own idea as researchers, is that measuring endogenous surfactant levels early in the morbidity of Covid-19 patients could provide a tool to differentiate between more severe courses developing from mild cases and provide information about the optimal time for outpatient surfactant treatment. Surfactant did not prevent Respiratory Distress Syndrome or Covid-19 [30]. But hopefully, the surfactant treatment will eliminate the surfactant deficiency component of the lung disease affect by Covid-19. We recommend clinical trial surfactant therapy in adult patients against Covid-19. Surfactant will probably get rid of surfactant deficiency and other aspects of lung immaturity. 


\section{CONCLUSION}

It can be concluded that surfactant has a contribution to the greater extent to improve lung's function. In addition, the first use of surfactant will probably be limited to the need of using intubation. This would better aid in reducing the effects of infectious pathogens during the period of their action. Waiting for the virus to be won and for new type II alveolar cells to produce the necessary surfactant independently. However, to reduce the risk of infection during the current Covid-19 outbreak, people should avoid crowds, mass events, ocean cruises, prolonged air travel and all persons with respiratory illness.

\section{DISCLAIMER}

The products used for this research are commonly and predominantly use products in our area of research and country. There is absolutely no conflict of interest between the authors and producers of the products because we do not intend to use these products as an avenue for any litigation but for the advancement of knowledge. Also, the research was not funded by the producing company rather it was funded by personal efforts of the authors.

\section{ETHICAL APPROVAL}

As per international standard or university standard ethical approval has been collected and preserved by the authors.

\section{ACKNOWLEDGEMENT}

Authors would like to thank DR. MD. ALMAMUN, MBBS,CCD, Emergency Medical Officer, Popular Medical College Hospital, Dhaka, Bangladesh and Sherri L. Fithian, NRCMA, RMA, Centura College, Richmond, Virginia, USA for furnishing our ideas and encouragement.

\section{COMPETING INTERESTS}

Authors have declared that no competing interests exist.

\section{REFERENCES}

1. Louisiana State University Health Sciences Center. ACE inhibitors and angiotensin receptor blockers may increase the risk of severe COVID-19; 2020.
2. Ajaykumar B. Coronavirus complications: How does Covid-19 affect your lungs? Narayana Health; 2020.

3. Hansen JE, Ampaya EP, Bryant GH. The branching pattern of airways and air spaces of a single human terminal bronchiole. Journal of Applied Physiology. 1975;38:983-989.

4. Saladin K. Human anatomy $3^{\text {rd }}$ Ed. McGraw-Hill. 2011;641-643.

5. Weinberger, Steven, Cockrill. Principles of pulmonary medicine Seventh Ed. Elsevier. 2019;126-129.

6. Ross, Michael H, Pawlina. Histology A Text and Atlas Sixth Edition; 2011.

7. Fehrenbach $\mathrm{H}$. Alveolar epithelial type II cell defender of the alveolus revisited. Respir Res. 2001;2:33-46.

8. International Union of Pure and Applied Chemistry IUPAC Gold Book, Surfactant Surface Active Agent. Last Revised.

9. Edwin JA, Veldhuizen, Henk $P$. Haagsman. Role of pulmonary surfactant components in surface film formation and dynamics. Biochimica et Biophysica Acta BBA Biomembranes. 2000;1467:255-270.

10. Young, Barbara. Wheater's functional histology: A text and colour atlas. O'Dowd, Geraldine, Woodford, Phillip (Sixth Ed.). Philadelphia, PA. pp. Ch.; 2014.

11. Perlman S. Another decade, another coronavirus. N Engl J Med.; 2020.

12. Wang C, Horby PW, Hayden FG, Gao GF. A novel coronavirus outbreak of global health concern. Lancet; 2020.

13. Alveoli and the breathing process. Retrieved 2013-10-30.

14. King RJ, Clements JA. Surface active materials from dog lung. Method of isolation. Am J. Physiol. 1972;223:707-14.

15. King RJ, Clements JA. Surface active materials from dog lung: Composition and physiological correlations. Am J Physiol. 1972;223:715-26.

16. Kulovich MV, Hallman M, Gluck L. The lung profile: Normal pregnancy. Am J Obstet Gynecol. 1979;135:57-63.

17. Hallman M, Spragg $\mathrm{R}$, Harrell JH, Moser KM, Gluck L. Evidence of lung surfactant abnormality in respiratory failure. J Clin Invest. 1982;70:673-83.

18. Liau OF, Barrett CR, Loomis AL, Cernansky G, Ryan SF. Diphosphatidylglycerol in experimental acute alveolar injury in the dog. J Lipid Res. 1984;25:678-83. 
19. Raju TNK, Vidyasagar O, Bhat R. Doubleblind controlled trial of single-dose treatment with bovine surfactant in severe hyaline membrane disease. Lancet. 1987;651-5.

20. Suzuki Y, Kogishi K, Fujita Y, Kina T, Nishikawa S. A monoclonal antibody to the 15,000 dalton protein associated with porcine pulmonary surfactant. Exp Lung Res. 1986;1l:61-73.

21. Whitsett JA, Ohning BL, Ross G. Hydrophobic surfactant-associated protein in whole lung surfactant and its importance for biophysical activity in lung surfactant extracts used for replacement therapy. Pediatr Res. 1986;20:460-7.

22. Said SI, Avery ME, Davis RK, Banerjee CM, El-Gohary M. Pulmonary surface activity in induced pulmonary edema. J Clin Invest. 1965;44:458-64.

23. Ikegami $M$, Jobe $A$, Glatz $T$. Surface activity following natural surfactant treatment in premature lambs. J Appl Physiol. 1981;51:306-12.

24. Ikegami $M$, Jacobs $H$, Jobe $A$. Surfactant function in respiratory distress syndrome. J Pediatr. 1983;102:443-7.

25. Jacobs $H$, Jobe $A$, Ikegami $M$, Glatz $T$, Jones S, Barajas L. Premature lambs rescued from respiratory failure with natural surfactant: Clinical and biophysical correlates. Pediatr Res. 1982;16:424-9.

26. Robertson B. Pathology and pathophysiology of neonatal surfactant deficiency in pulmonary surfactant. In: Robertson B, Van Golde LMG, Batenburg JJ, Eds. Pulmonary surfactant. Amsterdam: Elsevier Science Publishers. 1984;383-418.

27. Nilsson R, Grossmann G, Robertson B. Lung surfactant and the pathogenesis of neonatal bronchiolar lesions induced by artificial ventilation. Pediatr Res. 1978;12: 249-55.

28. Nilsson R, Grossmann G, Robertson B. Pathogenesis of neonatal lung lesions induced by artificial ventilation: Evidence against the role of barotrauma. Respiration. 1980;40:218-25.

29. Christian A, Devaux, Jean-Marc R, Philippe C. New insight on the antiviral effects of chloroquine against Coronavirus what to expect for COVID-19. International Journal of Antimicrobial Agents; 2020.

30. Jobe A, Ikegami M. Surfactant for the treatment of respiratory distress syndrome. The American Review of Respiratory Disease. 1987;136:1256-75.

(c) 2020 Ahmed et al.; This is an Open Access article distributed under the terms of the Creative Commons Attribution License (http://creativecommons.org/licenses/by/4.0), which permits unrestricted use, distribution, and reproduction in any medium, provided the original work is properly cited.

Peer-review history:

The peer review history for this paper can be accessed here: http://www.sdiarticle4.com/review-history/57720 